\title{
Detoxification and elimination of nicotine by nectar-feeding birds
}

\section{S. Lerch-Henning ${ }^{1}$, E. E. Du Rand ${ }^{1,2 *}$ and S. W. Nicolson ${ }^{1}$}

${ }^{1}$ Department of Zoology and Entomology, University of Pretoria, Private Bag X20, Hatfield 0028, South Africa

${ }^{2}$ Department of Biochemistry, University of Pretoria, Private Bag X20, Hatfield 0028, South Africa

*Author for correspondence: Dr. Ezette du Rand

$$
\begin{aligned}
& \text { E-mail: ezette.durand@up.ac.za } \\
& \text { Tel: +27 } 845859954 \\
& \text { Fax: +27 } 123625242
\end{aligned}
$$

Keywords: detoxification, excretion, nectar, nectar-feeding birds, nicotine, osmoregulation 


\section{Abstract}

Many dilute nectars consumed by bird pollinators contain secondary metabolites, potentially toxic chemicals produced by plants as defences against herbivores. Consequently, nectar-feeding birds are challenged not only by frequent water excess, but also by the toxin content of their diet. High water turnover, however, could be advantageous to nectar consumers by enabling them to excrete secondary metabolites or their transformation products more easily. We investigated how the alkaloid nicotine, naturally present in nectar of Nicotiana species, influences osmoregulation in white-bellied sunbirds Cinnyris talatala and Cape white-eyes Zosterops virens. We also examined the metabolic fate of nicotine in these two species to shed more light on the post-ingestive mechanisms that allow nectar-feeding birds to tolerate nectar nicotine. A high concentration of nicotine $(50 \mu \mathrm{M})$ decreased cloacal fluid output and increased its osmolality in both species, due to reduced food intake that led to dehydration. White-eyes excreted a higher proportion of the ingested nicotine-containing diet than sunbirds. However, sugar concentration did not affect nicotine detoxification and elimination. Both species metabolised nicotine, excreting very little unchanged nicotine. Cape white-eyes mainly metabolised nicotine through the cotinine metabolic pathway, with norcotinine being the most abundant metabolite in the excreta, while white-bellied sunbirds excreted mainly nornicotine. Both species also utilized phase II conjugation reactions to detoxify nicotine, with Cape white-eyes depending more on the mercapturic acid pathway to detoxify nicotine than white-bellied sunbirds. We found that sunbirds and white-eyes, despite having a similar nicotine tolerance, responded differently and used different nicotine-derived metabolites to excrete nicotine. 


\section{Introduction}

Secondary metabolites are widespread in floral nectars (Adler 2000) including those consumed by bird pollinators. The paradox of toxins in a floral reward has led to a variety of studies examining different hypotheses for adaptive functions of toxins in nectar (Stevenson et al. 2017; Adler 2000). Possible beneficial effects include increasing specialization in plant-pollinator interactions and protection of nectar from microbes or unwanted consumers. In the case of nectars for birds, the dilute nature of these nectars (Johnson and Nicolson 2008) is relevant to the challenge of minimising any negative consequences of nectar toxins. Nectar sugar concentrations are highly variable and specialist nectar-feeding birds compensate for low sugar concentrations by consuming greater volumes to maintain a constant energy intake (Martínez del Rio et al. 2001; Nicolson and Fleming 2003). This compensatory feeding means that toxic secondary metabolites could potentially be consumed in large quantities if the nectar is very dilute (Lerch-Henning and Nicolson 2013). On the other hand, the high water turnover experienced by these birds (Nicolson and Fleming 2014) may also be advantageous in facilitating the excretion of secondary metabolites.

Specialist nectarivores such as sunbirds (Nectariniidae), honeyeaters (Meliphagidae) and hummingbirds (Trochilidae) consume several times their body mass in food per day when foraging on very dilute nectars (McWhorter and del Rio 1999; Nicolson and Fleming 2003; Purchase et al. 2013a). Sunbirds and honeyeaters are able to shunt excess water through the intestine, reducing the load on the kidneys (Beuchat et al. 1990; McWhorter et al. 2003; Purchase et al. 2013a). It is conceivable that they may excrete water-soluble secondary metabolites rapidly with the excess 
water passing through the intestine, thus avoiding absorption and the subsequent requirement for post-absorptive strategies such as detoxification. Hummingbirds, however, do not modulate their intestinal water absorption (McWhorter and del Rio 1999; Hartman Bakken and Sabat 2006). All three lineages of specialist nectarivores produce dilute cloacal fluid with extremely low osmolality when feeding on dilute nectars, thus conserving vital electrolytes while excreting large volumes of excess water (Fleming and Nicolson 2003; Nicolson and Fleming 2014). They can also cope with temporary dehydration induced by restriction to concentrated nectars (Fleming et al. 2004a). Generalist or occasional nectar-feeding birds, such as white-eyes, bulbuls, orioles and weavers, consume even more dilute nectars than specialist nectarivores (Johnson and Nicolson 2008), but nectar forms a smaller portion of their diets, which also include fruit, seeds and insects. Consequently, these generalist or occasional nectar-feeding birds may have different mechanisms to cope with secondary metabolites in their diets compared to nectar specialists.

Consuming dilute nectars may also influence toxin absorption via the paracellular pathway. Paracellular absorption is an important route of glucose uptake in small birds (Caviedes-Vidal et al. 2007) and has been demonstrated in white-bellied sunbirds Cinnyris talatala and in silvereyes Zosterops lateralis (Napier et al. 2008; Napier et al. 2014). Paracellular absorption makes birds vulnerable to small water-soluble toxins such as nicotine (Karasov 2011; Karasov et al. 2012). Karasov (2011) demonstrated that pigeons absorbed $44 \%$ of a dose of nicotine via this route. However, dilution of the diet reduces the proportion of glucose absorbed by the paracellular route (Napier et al. 2008) which could reduce the amount of water-soluble toxins absorbed.. 
The most important mechanisms responsible for toxin tolerance in birds are likely to involve metabolism and elimination of ingested toxins. Detoxification is a post-ingestive metabolic tolerance mechanism involving the enzymatic biotransformation of xenobiotics into less toxic or non-toxic metabolites that can easily be eliminated. Animals use a cascade of enzymes to catalyse the oxidation, reduction, and hydrolysis of xenobiotics (phase I) and/or their conjugation to functional groups (phase II). Phase III detoxification encompasses the movement of unmodified toxins, unconjugated phase I or conjugated phase II products across lipid membranes out of cells by a range of transporter proteins and ATP-dependent pumps, followed by elimination through the kidneys (Liska 1998; Dearing et al. 2005, Sorensen and Dearing, 2006, Almeida et al. 2016). The action of detoxification enzymes, the synthesis of conjugation substrates and the active elimination of the by-products by the kidneys all require energy (Karasov and Martínez del Rio 2007; Au et al. 2013). Increased energy expenditure associated with detoxification processes has been observed in birds challenged with secondary metabolites in their diet (Guglielmo et al. 1996; Barceló et al. 2016). This suggests that there may be a tradeoff between the energy birds gain by passively absorbing water-soluble nutrients such as glucose through the paracellular route and the increased metabolic demand to elminate the water-soluble nectar toxins that are absorbed concurrently.

Nicotine is a broadly toxic secondary metabolite produced by Nicotiana species as a defence against herbivores. It mimics the neurotransmitter acetylcholine by binding to the nicotinic acetylcholine receptors found at neuromuscular junctions (Baldwin 2001; Steppuhn et al. 2004). Nicotine levels in the leaves and nectar of Nicotiana species are correlated with each other and inversely related to the extent of cross-pollination (Adler et al. 2012). Nectar nicotine concentrations range from 0 to $42 \mu \mathrm{M}$ (Kessler et al. 2012; Adler et al. 2012). Kessler et al. (2012) 
showed that variance in nectar nicotine concentration in $N$. attenuata strongly affected the foraging behaviour of hummingbird pollinators. The Argentinian species N. glauca is a widespread invasive plant and in South Africa, as in Israel, it is a valuable nectar resource for sunbirds in dry regions (Tadmor-Melamed et al. 2004; Geerts and Pauw 2009).

The repellent effect of nicotine on nectar-feeding birds depends on species, as well as the nicotine and nectar sugar concentrations. Specialist nectarivores such hummingbirds (Archilochus alexandrei) and sunbirds (Cinnyris oseus, C. talatala) and more generalist nectar-feeding birds such as white-eyes (Zosterops virens) and bulbuls (Pycnonotus tricolor) demonstrate dosedependent deterrence and with higher nectar sugar concentrations lead to increased nicotine tolerance (Tadmor-Melamed et al. 2004; Kessler et al. 2010; Kessler et al. 2012; Lerch-Henning and Nicolson 2013). Overall, white-bellied sunbirds and Cape white-eyes exhibit an intermediate level of tolerance to nicotine, comparable to blackchinned hummingbirds (Archilochus alexandrei) but approx. 3-4 times higher than Palestine sunbirds (C. oseus) and 4-5 times lower than darkcapped bulbuls ( $P$. tricolor). Remarkably little is known about the post-ingestive mechanisms utilized by nectar-feeding birds to tolerate dietary toxins. Besides detoxification mechanisms, it is also feasible that nectar-feeding species that can modulate intestinal water absorption will excrete water-soluble toxins such as nicotine rapidly with the excess water passing through the intestine. On a physiological level, high nicotine concentrations in artificial nectar negatively affect compensatory feeding, gut transit time and assimilation efficiency of sunbirds and whiteeyes (Tadmor-Melamed et al. 2004; Lerch-Henning and Nicolson 2015). As yet, the effects of nicotine and other nectar secondary metabolites on osmoregulation are still unknown. 
Here we investigated the effects of consuming nicotine on osmoregulation in two small nectarivores, C. talatala, and Z. virens, with a similar tolerance to nectar nicotine. We also examined the metabolic fate of nicotine in these two bird species to shed more light on the postingestive mechanisms that allow nectar-feeding birds to tolerate dietary nicotine. We predicted that (a) a high nicotine concentration would have a dehydration effect in both species due to the deterrent effect of nicotine; (b) nectar sugar concentration would influence the excretion of nicotine and its metabolites; and (c) the transformation products of nicotine oxidation and glucuronidation would be present in the excreta of birds exposed to dietary nicotine.

\section{Material and Methods}

\section{Study species and their maintenance}

During the non-breeding season (April-June) of 2011-2013, 12 white-bellied sunbirds (C. talatala, mean body mass $\pm \mathrm{SE}=8.24 \pm 0.19 \mathrm{~g})$ and 13 Cape white-eyes $(Z$. virens, mean body mass $=$ $10.69 \pm 0.18 \mathrm{~g}$ ) were mist-netted in Jan Cilliers Park, Pretoria and at the Pretoria National Botanical Gardens. Birds were acclimated to captivity and to artificial diets in an outdoor aviary $(8 \times 2 \times 5$ m) at the experimental farm of the University of Pretoria. Two weeks prior to experiments, birds were moved to individual cages $(30 \times 42 \times 46 \mathrm{~cm}) \mathrm{kept}$ in a climate-controlled room. The climatecontrolled room was maintained at $20 \pm 2^{\circ} \mathrm{C}$ on a $12: 12 \mathrm{~h}$ light : dark cycle, where dawn and dusk were simulated with $0.5 \mathrm{~h}$ of dimmed light before and after the full light period that started at 08:00. After the study was concluded, birds were released at the place of capture. 
The maintenance diet for both species consisted of an artificial nectar solution containing 0.6 M sucrose and the nutritional supplement Ensure ${ }^{\circledR}$ (Abbott Laboratories, Johannesburg, South Africa). In addition, for white-eyes, seasonal fruits such as papaya, apple and banana with moistened ProNutro® cereal (Becketts CNR, Wadeville, South Africa) were provided. The maintenance diet and water were presented ad libitum in $20 \mathrm{ml}$ inverted stoppered syringes and renewed daily, together with fruits. Water baths were also provided.

\section{Experimental procedure}

In the first trial, sunbirds $(n=8)$ and white-eyes $(n=9)$ were exposed to four test diets: $0.63 \mathrm{M}$ sucrose containing 0, 0.5, 5 or $50 \mu \mathrm{M}$ nicotine (from Sigma, (-)-nicotine, N3876) and cloacal fluid (CF) was collected in liquid paraffin with the following protocol. Before $08 \mathrm{~h} 00$, birds were moved from their maintenance cages to experimental cages $(29 \times 41 \times 36 \mathrm{~cm})$ with a bottom tray filled with liquid paraffin. A plastic mesh (vegetable bagging) stretched tightly over the tray prevented birds from making contact with the paraffin. After $6 \mathrm{~h}$ birds were moved back to their maintenance cages. As soon as birds were placed into experimental cages they were provided with a test diet and after $6 \mathrm{~h} \mathrm{CF}$ was collected from each tray separately with a plastic pipette and stored in labeled plastic jars. The following day when the CF and the paraffin had separated, the exact volume of $\mathrm{CF}$ was measured in a graduated glass cylinder. The samples were frozen for later analysis of osmolality. Osmolality of CF was measured (in duplicate and in random order) using a freezing point depression osmometer (OSMOMAT ${ }^{\circledR}$ 030, Gonotec GmbH, Germany).

For the second trial (sunbirds and white-eyes, $n=4$ ), two test diets were used: $0.25 \mathrm{M}$ and $1 \mathrm{M}$ sucrose, both containing $50 \mu \mathrm{M}$ nicotine. Birds were exposed twice to the same diet, since it was 
necessary to collect CF with two different methods. First, CF was collected in liquid paraffin (same

protocol as above) to measure the total volume of excreta and secondly, CF was collected on a dry plastic tray to enable analysis of excreta for nicotine metabolites. To do so, birds were moved into small experimental cages $(43 \times 27 \times 42 \mathrm{~cm})$ while feeding on the test diets and excreta were allowed to evaporate at the bottom of the cage on a plastic tray. After $6 \mathrm{~h}$, excreta were collected by adding a known volume of distilled water $(10-15 \mathrm{ml})$ and scrubbing off the plastic tray with the water. Collected samples were frozen at $-20^{\circ} \mathrm{C}$ until further analysis.

Test diets were presented in random order to individuals for a duration of $6 \mathrm{~h}$. After each experimental day, one day of maintenance diet followed. Feeders and birds were weighed before and after the experiment ( $\pm 0.1 \mathrm{mg}$, Mettler Toledo AG-64, Microsep Ltd, Johannesburg). A cup containing liquid paraffin (to avoid evaporative mass loss) was placed underneath each feeder to correct food intake for possible spills. Volumetric intake ( $\mathrm{ml}$ in $6 \mathrm{~h}$ ) was calculated using food intake (g) divided by the relative density of the sucrose solutions $(\mathrm{g} / \mathrm{L})$. Nicotine intake $(\mu \mathrm{g})$ was calculated using volumetric intake of test diet $(\mathrm{ml}) \times$ nicotine concentration $(\mu \mathrm{M})$ divided by the molar mass of nicotine (g/mol). Sugar intake (g) was calculated using volumetric intake of test diet $(\mathrm{ml}) \times$ sucrose concentration $(\mathrm{M})$ divided by the molar mass of sucrose $(\mathrm{g} / \mathrm{mol})$.

\section{Nicotine metabolite analysis}

Chemicals and reagents. All reagents were of analytical grade unless otherwise indicated. Nicotine and methanol CHROMASOLV ${ }^{\circledR}$ for HPLC were purchased from Sigma-Aldrich (Louis, MO, USA). All solutions and dilutions were prepared with double distilled de-ionised water, produced 
by an ELGA PURELAB Ultrawater purification system from Veolia Water Systems Ltd (High Wycombe, UK) unless otherwise stated.

Sample preparation. The excreta samples were lyophilised. Dried samples were powdered using a glass rod before adding $500 \mu 1$ methanol. Samples were sonified using a Sonifier® Cell Disrupter B-30 fitted with a microtip (Branson Ultrasonics Corporation, Danbury, CT, USA) in $3 \times 15 \mathrm{~s}$ pulses with 10 s cooling in between (settings: pulsed; Output control 3; \% Duty cycle 60). Subsequently, the samples were centrifuged at $12000 \mathrm{x} g$ for $10 \mathrm{~min}$ and the supernatants were decanted while the pellets were discarded. The samples were dried using a Reacti-Vap ${ }^{\mathrm{TM}}$ III Evaporator (Thermo Scientific, IL, USA). Dried samples were stored at $4{ }^{\circ} \mathrm{C}$ until further analysis.

LC/MS/MS analysis. Dried samples were reconstituted in $300 \mu 150 \%(\mathrm{v} / \mathrm{v})$ methanol for LC/MS/MS analysis. The chromatographic analysis was performed on a Waters ACQUITY UPLC $^{\circledR}$ system (Milford, MA, USA) coupled to a SYNAPT ${ }^{\mathrm{TM}}$ G2 mass spectrometer (Waters Corporation, Micromass UK Ltd, Manchester, UK), with hybrid quadrupole/ion mobility/orthogonal acceleration-time of flight geometry and an electrospray ionisation (ESI) source. Separations were carried out on an ACQUITY UPLC ${ }^{\circledR}$ BEH amide column $(100 \times 2.1$ $\mathrm{mm}, 1.7 \mu \mathrm{m}$ ) obtained from Waters (Milford, MA, USA). Mobile phase A consisted of $0.1 \%(\mathrm{v} / \mathrm{v})$ formic acid aqueous solution and mobile phase B consisted of 95\% (v/v) acetonitrile and $0.2 \%$ (v/v) formic acid aqueous solution containing $10 \mathrm{mM}$ ammonium acetate. The following gradient was used: 0 - 10 minutes, 100 - 50\% B; 10 - 13 minutes, 50 - 40\% B; 13 - 13.3 minutes, 40 - 100\% B; 13.3 - 20 minutes, $100 \% \mathrm{~B}$. The flow rate of the mobile phase was $0.35 \mathrm{ml} / \mathrm{min}$ and the injection volume was $5 \mu 1$. Mass spectrometer conditions were optimised using a nicotine standard solution. 
Optimal conditions included a capillary voltage of $3 \mathrm{kV}$ and a cone voltage of $15 \mathrm{~V}$. Mass spectra were acquired in positive ion mode $\left([\mathrm{M}+\mathrm{H}]^{+}\right)$. To ensure accurate mass acquisition, a lock-mass of leucine encephalin was used. Selective ion monitoring was used to detect specific fragment ions and the mass spectra were scanned for molecules with the following mass to charge ratios $(\mathrm{m} / \mathrm{z})$ : nicotine $(\mathrm{m} / \mathrm{z}, 163)$, nicotine- $N$-oxide $(\mathrm{m} / \mathrm{z}, 179), \mathrm{N}$-methylnicotinium ion $(\mathrm{m} / \mathrm{z}, 177)$, nicotine $N$ glucuronide ( $\mathrm{m} / \mathrm{z} 340)$, nicotine $N$-oxide-glucuronide $(\mathrm{m} / \mathrm{z} 356)$, 4-(methylamino)-1-(3-pyridyl)-1butanone $(\mathrm{m} / \mathrm{z}$ 179), nornicotine $(\mathrm{m} / \mathrm{z}$ 149), 4-oxo-4-(3-pyridyl)-butanamide $(\mathrm{m} / \mathrm{z} \quad 178)$, nornicotine-glucuronide $(\mathrm{m} / \mathrm{z} 326)$, nicotine-GSH $(\mathrm{m} / \mathrm{z} 470)$, cotinine $(\mathrm{m} / \mathrm{z} \quad 177)$, cotinine methonium ion $(\mathrm{m} / \mathrm{z}, 191)$, norcotinine $(\mathrm{m} / \mathrm{z}, 163), N$-hydroxymethly-norcotinine $(\mathrm{m} / \mathrm{z} 192)$, norcotinine-glucuronide $(\mathrm{m} / \mathrm{z} 276)$, cotinine- $N$-oxide $(\mathrm{m} / \mathrm{z} 193)$, cotinine- $N$-oxide glucuronide $(\mathrm{m} / \mathrm{z}$ 317), cotinine- $N$-glucuronide $(\mathrm{m} / \mathrm{z} 354)$, cotinine-GSH $(\mathrm{m} / \mathrm{z} 484), 3$ '-hydroxy-cotinine-GSH $(\mathrm{m} / \mathrm{z}$ 369), 4-hydroxy-4-(3-pyridyl)-butanoic acid ( $\mathrm{m} / \mathrm{z}, 181)$, 3-pyridylacetic acid ( $\mathrm{m} / \mathrm{z}, 137)$, 4-(3pyridyl)-butanoic acid $(\mathrm{m} / \mathrm{z}, 165)$, 3-pyridylacetic acid $(\mathrm{m} / \mathrm{z}$ 137), glucuronide $(\mathrm{m} / \mathrm{z} 178)$, glutathione $(\mathrm{GSH}, \mathrm{m} / \mathrm{z}$ 308) and nicotine $+\mathrm{N}$-acetylcysteine $(\mathrm{m} / \mathrm{z}$ 386). Possible nicotine related metabolites were identified in the bird excreta samples (based on the known molecular ions and the associated characteristic fragment ion patterns) and compared between dietary treatment groups. In addition, two standards were used (nicotine and cotinine) and retention times of all possible nicotine related identified compounds were related to the retention times of these standards based on their structures to further eliminate unrelated compounds. Nicotine and nicotine-derived metabolites detected in excreta samples were expressed as a percentage of the total amount of nicotine ingested. 


\section{Statistical analysis}

We performed the statistical analysis using IBM ${ }^{\circledR}$ SPSS Statistics (version 23). The data is nonparametric and since the same individual was used for all four test treatments, we followed a dependent sample procedure. First, to analyse whether nicotine concentrations have a significant effect on the measured parameters, we performed for each parameter (intake, excretion, osmolality and the ratio of $\mathrm{CF} /$ intake) a Friedman-Test followed by Wilcoxon pairwise comparisons. Secondly, to analyse if species differ in the excreta osmolality and in the ratio of CF/intake, we performed a Friedman-Test followed by Mann-Whiney U-Test as post-hoc test. We used a $t$-test for dependent samples to test if sucrose concentration (low and high) had an effect on the excretion of nicotine $(\mu \mathrm{g})$, in both species since we used the same individual for both treatments. In addition, to analyse whether species had an effect on the excretion of nicotine and nicotine-derived metabolites we performed a $t$-test for independent samples on the intensity values of each of the 8 identified compounds. All data are presented as mean values $\pm \mathrm{SE}$ and for all tests the level of significance was $\mathrm{p}<0.05$.

\section{Results}

Both white-bellied sunbirds and Cape white-eyes showed a significant decrease in food intake (sunbirds: $\chi^{2}=15.45, \mathrm{df}=3, \mathrm{p}=0.001$ and white-eyes: $\chi^{2}=16.33, \mathrm{df}=3, \mathrm{p}=0.001 ;$ Fig. 1 ) and in CF production (sunbirds: $\chi^{2}=16.35, \mathrm{df}=3, \mathrm{p}=0.001$ and white-eyes: $\chi^{2}=15.13, \mathrm{df}=3, \mathrm{p}=$ 0.002; Fig. 1). Intake and excretion of the highest nicotine concentration was significant lower than that of other test diets (sunbirds: $p=0.012$; white-eyes: $\mathrm{p}=0.008$ ). The highest nicotine concentration caused a significant increase in CF osmolality in sunbirds $\left(\chi^{2}=15.12, \mathrm{df}=3, \mathrm{p}=\right.$ 
0.002; Fig 2) and white-eyes $\left(\chi^{2}=11.80, \mathrm{df}=3, \mathrm{p}=0.008\right.$; Fig. 2$)$. In birds feeding on the highest nicotine concentration, we measured CF osmolalities of $578 \pm 97 \mathrm{mOsm} / \mathrm{kg}$ in sunbirds and $243 \pm$ $41 \mathrm{mOsm} / \mathrm{kg}$ in white-eyes. We found a significant effect of bird species on osmolality $\left(\chi^{2}=26.38\right.$, $d d f=3, p<0.001)$ and bird species differ significantly when feeding on the low $\left(U_{13}=9, Z=-\right.$ 2.60, $\mathrm{p}=0.009)$ and high $\left(\mathrm{U}_{13}=12, \mathrm{Z}=-2.31, \mathrm{p}=0.021\right)$ nicotine concentration. The ratio of $\mathrm{CF}$ excreted to food intake in sunbirds and white-eyes decreased significantly at the highest nicotine concentration compared to the other diets $\left(\chi^{2}=15.45, \mathrm{df}=3, \mathrm{p}=0.001\right.$ and $\chi^{2}=18.20, \mathrm{df}=3, \mathrm{p}<$ 0.001, respectively; Fig. 2) and species had a significant effect on this parameter $\left(\chi^{2}=31.52, \mathrm{df}=\right.$ $3, \mathrm{p}<0.001$ ). Sunbirds and white-eyes showed a significant difference in the ratio of CF/intake while feeding on the control $\left(\mathrm{U}_{13}=8, \mathrm{Z}=-2.69, \mathrm{p}=0.007\right)$, low $\left(\mathrm{U}_{13}=1, \mathrm{Z}=-3.37, \mathrm{p}=0.001\right)$ and high nicotine concentrations $\left(\mathrm{U}_{13}=4, \mathrm{Z}=-3.08, \mathrm{p}=0.002\right)$, although both species ingested similar amounts of nicotine (see Table 1 for values).

When low and high sucrose concentrations were compared, there were no significant difference in the amounts of nicotine excreted (see Table 2 for values) in either species (sunbirds: $t=0.215$, df $=3, \mathrm{p}=0.844$; white-eyes: $t=2.901, \mathrm{df}=3, \mathrm{p}=0.062)$. Hence, the results were averaged across both sucrose concentrations. Both species metabolised nicotine with very little unmetabolised nicotine recovered in the excreta: unchanged nicotine accounted for only 0.05 and $0.13 \%$ of the total amount of nicotine ingested for sunbirds and white-eyes, respectively. The major metabolites detected were norcotinine, cotinine methonium ion and nornicotine. Phase II metabolites were also detected: nornicotine-glucuronide, norcotinine-glucuronide and cotinine-glutathione (Fig 3). In addition to these nicotine-derived metabolites, birds also excreted an intermediate of the mercapturic acid pathway, nicotine-N-acetylcysteine (nicotine-NAC). We also detected 
substantial levels of glutathione (GSH) in the excreta; however, this compound was probably split off from a nicotine-glutathione conjugation product.

Nicotine and nicotine-derived metabolites detected in excreta samples are expressed as a percentage of the total amount of nicotine ingested and differed between bird species (see Table 2). White-eyes excreted slightly higher amounts of unchanged nicotine than sunbirds $(0.034 \pm$ 0.002 and $0.024 \pm 0.002 \mu \mathrm{g}$ nicotine, respectively; $t=6.74, \mathrm{df}=14, \mathrm{p}=0.014)$. In addition, whiteeyes excreted significantly more norcotinine, GSH and nicotine-NAC than sunbirds (for statistical values see Table 3).

\section{Discussion}

Nectar-feeding birds may use their high water turnover rate to flush out secondary compounds and any biotransformation products. We analysed the excreta of sunbirds and white-eyes for nicotine and nicotine-derived metabolites and found that both species are able to metabolise nicotine. We predicted that if nicotine was presented in dilute nectar this would facilitate the excretion of the unchanged toxin due to the higher water turnover; however, this was not confirmed. A high concentration of dietary nicotine induced a physiological response similar to dehydration. We

discuss these findings in terms of the possible osmoregulatory consequences of encountering nicotine in nectar and the detoxification mechanisms that nectarivores could use to cope with secondary compounds present in nectar. 


\section{Water balance and secondary metabolites}

The drastic reduction in food intake observed at high nicotine concentrations could be due to deterrence or post-ingestive consequences (Lerch-Henning and Nicolson 2013; Lerch-Henning and Nicolson 2015). Largely due to the reduced food intake, we observed a significant reduction in $\mathrm{CF}$ volume and an increase in $\mathrm{CF}$ osmolality in both species at high nicotine concentrations. Sunbirds excreted three times less CF $(0.15 \mathrm{ml} / 6 \mathrm{~h})$ than white-eyes $(0.44 \mathrm{ml} / 6 \mathrm{~h})$, i.e. white-eyes excreted a higher proportion of the ingested diet than sunbirds. The CF osmolality of sunbirds increased 14 times while that of white eyes increased four times compared to birds receiving the nicotine-free diet. These observations mirror the physiological response to dehydration in birds. When feeding on concentrated nectars, birds conserve water by reducing production of cloacal fluid and increasing its osmolality (Fleming and Nicolson 2003; Fleming et al. 2004a). Sunbirds reduced $\mathrm{CF}$ output to $0.004 \mathrm{ml} / \mathrm{h}$ on a concentrated $2.5 \mathrm{M}$ sucrose diet compared to $1.4 \mathrm{ml} / \mathrm{h}$ on a dilute 0.25 M sucrose diet (Fleming et al. 2004a). High CF osmolalities ( $450 \mathrm{mOsm} / \mathrm{kg}$ ) were recorded when birds were presented with either $2.5 \mathrm{M}$ sucrose or $0.63 \mathrm{M}$ sucrose containing 200 mM NaCl (Fleming and Nicolson 2003; Purchase et al. 2013b). White-bellied sunbirds are able to modulate their glomerular filtration rate, effectively shutting down urine production to avoid potential dehydration during the overnight fast period (Fleming et al. 2004b; Purchase et al. 2013a). Less is known about the water conservation abilities of white-eyes, but a field study of Australian silvereyes Zosterops lateralis showed considerable variation in water turnover (Rooke et al. 1983). Our data confirm that white-eyes are able to conserve water, although not as well as sunbirds.

It is also possible that the decreased CF output and increased CF osmolality we observed are not only due to reduced food intake, but also in part due to the antidiuretic effect of nicotine. Nicotine 
can have an antidiuretic effect in humans and other mammals through its action on the antidiuretic hormone vasopressin (Burn et al. 1945; De Souza and Silva Jr 1977). It is possible that in birds nicotine also stimulates the pituitary gland to release arginine vasotocin, the avian analogue of the mammalian vasopressin, contributing to the dehydration-like response. Arginine vasotocin concentration increases in the plasma of white-bellied sunbirds fed concentrated sucrose diets (Gray et al. 2004). An antidiuretic compound is described as lowering water output even though water intake is unchanged. In nectar-feeding birds, food and water intake cannot be separated, so we cannot draw any conclusion regarding the antidiuretic effect of nicotine.

In contrast, some plant secondary metabolites such as phenolics and terpenes appear to have diuretic effects on herbivore consumers. These compounds cause an increase in water intake compared to a control diet, an increase in urine output in relation to ingested water and a decrease in urine osmolality (Dearing et al. 2001; Dearing et al. 2002). In these studies, the water balance of specialist herbivores was less affected by plant defence chemicals than that of generalist herbivores (Dearing et al. 2001; Dearing et al. 2002). This is confirmed by a recent study of seedeating birds in which increased water intake on a diet supplemented with phenols was recorded in common diuca-finches $D$. diuca but not in rufous-collared sparrows Zonotrichia capensis which are more accustomed to consuming toxins (Barceló et al. 2016).

\section{Detoxification of nicotine}

Sunbirds and white-eyes, after consuming $50 \mu \mathrm{M}$ nicotine in artificial nectar, excreted nicotinederived metabolites similar to those found in humans, other mammals and insects. In humans, 70 $-80 \%$ of the absorbed nicotine is converted to cotinine before being metabolised further, and about 
$10-15 \%$ of the absorbed nicotine dose appears as unchanged cotinine in the urine (Hukkanen et al. 2005; Rangiah et al. 2011). Nectar-feeding birds mainly excreted norcotinine or nornicotine. In white-eye excreta, the major nicotine metabolite detected was norcotinine, which is the result of oxidative N-demethylation of nicotine (phase I detoxification reactions; see Fig. 3). In sunbirds, the major metabolite detected in excreta was nornicotine, the product of $\mathrm{N}$-demethylation of nicotine (see Fig. 3). Cotinine methonium was also detected in both bird species at lower levels but no cotinine could be detected. All three of these metabolites are present in the urine of humans and other mammals exposed to nicotine, nornicotine as one of the major urinary metabolites and norcotinine and cotinine methonium being two minor metabolites (Hukkanen et al. 2005; Rangiah et al. 2011).

Birds also appear to utilise the major conjugation pathways when detoxifying nicotine including glucuronidation and glutathione conjugation, the first step of the mercapturic acid pathway. We detected norcotinine-glucuronide, nornicotine-glucuronide, cotinine-glutathione and nicotineNAC. In addition, glutathione was detected in the excreta of both species. Conjugation of nicotine to glucuronic acid (glucuronidation) is an important reaction in the metabolism of nicotine (Hukkanen et al. 2005; Chen et al. 2010; Rangiah et al. 2011). In humans, up to $30 \%$ of urinary nicotine and cotinine are conjugated to glucuronides (Meger et al. 2002; Hukkanen et al. 2005; Chen et al. 2010).

Glucuronic acid is a derivative of endogenous glucose, and therefore expensive to excrete: its presence in urine is an indication that detoxification may impact animals energetically (Mangione et al. 2004; Sorensen et al. 2005). The glucuronidation pathway is a major route of phenolic 
detoxification in birds (Jakubas et al. 1993; Guglielmo et al. 1996; Barceló et al. 2016). Glucuronic acid output is considered a biomarker of the capacity to detoxify phenolics (Ríos et al. 2012; Barceló et al. 2016) and may have high energetic costs (Guglielmo et al. 1996; Barceló et al. 2016) in birds. However, compensatory feeding may obviate any negative effects on the energy balance of birds. We did not find a significant difference in the amount of nicotine and its metabolites excreted when sunbirds and white-eyes fed on low and high sucrose concentrations; although this result might be a reflection of the small sample size.

In addition to glucuronic acid conjugation products, we also detected a glutathione conjugation product (cotinine-glutathione) and one mercapturic acid derivative, nicotine-NAC. In the mercapturic acid pathway, glutamate and glycine are split off from the glutathione molecule conjugated to the xenobiotic and the remaining cysteine from the glutathione molecule is acetylated to form mercapturic acids, which are excreted in urine (see Fig. 3) (Gloss et al. 2014). In general, higher levels of glutathione in excreta are associated with the detoxification and elimination of toxins from the body (Rinaldi et al. 2002; Lushchak 2012). Although glutathione conjugation products are not associated with nicotine detoxification in humans and other mammals, the glutathione conjugation pathway has been linked to the detoxification of nicotine in honeybees, Apis mellifera (Du Rand et al. 2015).

It is possible that fast gut transit rates help specialist nectar-feeding birds to eliminate secondary compounds and their transformation products from their bodies faster. Previously we found that high nectar nicotine did not affect gut transit time of white-bellied sunbirds (Lerch-Henning and Nicolson 2015). Sunbirds and honeyeaters are able to shut a portion of the excess water they ingest 
on dilute nectar through the intestine (Purchase et al. 2013a). Nicotine, a water-soluble molecule, could be flushed out with the excess water, thereby avoiding absorption. However, we found very little unchanged nicotine in the excreta which suggests that nicotine was absorbed into the blood stream, catabolised in the liver and excreted as metabolites by the kidney. Nicotine can be absorbed across the intestinal epithelium via two possible routes. Nicotine in its unionized form is an amphipathic molecule that can easily cross intestinal cell membranes passively. However, at pH levels below 8, it exists in its water-soluble cationic forms that cannot easily pass through membranes. At physiological pH (7.4), 70\% of the nicotine is ionized, but because of its small size (162 kDa) it could be absorbed across the intestinal epithelium through paracellular spaces by diffusion or solvent drag (Karasov et al. 2012). Karasov (2011) showed that pigeons absorbed $44 \%$ of a nicotine dose through the paracellular route.

The possibility that sunbirds might rapidly excrete substantial amounts of unchanged nicotine while shunting water through the gut was not excluded by our results. To ensure a functional response and that nicotine and any metabolites would be present at levels above the limits of detection, we chose a nicotine concentration at the high end of the natural concentration range in Nicotiana nectar (Kessler et al. 2012). The high concentration of nicotine used to investigate its metabolic fate reduced the food intake of the birds which led to them conserving water. On a diet of $50 \mu \mathrm{M}$ nicotine sunbirds produced almost three times less cloacal fluid over a $6 \mathrm{~h}$ period than white-eyes. This in part could explain the lower recovery of ingested nicotine in sunbirds: almost half $(\sim 38 \%)$ of the percentage recovered in white eyes $(\sim 72 \%$, see Table 3$)$. One of the mechanisms used by sunbirds to conserve water is reducing glomerular filtration (Fleming et al. 2004b; Purchase et al. 2013a), which would also result in lower excretion of solutes, including nicotine 
and its metabolites. In future studies, the use of radiolabeled nicotine and a lower concentration of nicotine in dilute artificial nectar will not only increase the limit of detection of nicotine and any nicotine-derived metabolites but will also ensure that the birds experience a high water turnover rate and avoid the potential trade-off between toxin elimination and water conservation.

\section{Detoxification strategies of birds}

Sunbirds and white-eyes appear to use similar oxidation and reduction reactions in combination with glucuronidation and glutathione conjugation to detoxify nicotine (Fig. 3). However, there were noticeable inter-species differences in the levels of certain nicotine-derived metabolites excreted in the CF (see Table 3). White-eyes excreted substantially more norcotinine, GSH and NAC-nicotine, which could indicate that white-eyes rely more heavily on metabolising nicotine via the cotinine pathway and mercapturic acid pathway than sunbirds. The glucuronic acid outputs of these two nectar-feeding species with a similar nicotine tolerance were not substantially different for the same nicotine intake. An exploratory study investigating secondary metabolite tolerance in granivorous birds, using glucuronic acid output as a biomarker of detoxification capacity, also found no interspecific differences in glucuronic acid excretion regressed against tannic acid intake (Ríos et al. 2012).. The authors suggested that the higher tannic acid tolerance of the generalist Z. capensis might be due to reliance on alternative detoxification routes to glucuronidation, such as ornithine conjugation or rapid excretion (Green et al., 2005; Jakubas et al., 1993). Glucuronic acid output might be a good biomarker for detoxification in birds, but not necessarily for detoxification capacity or the ability to detoxify and tolerate a particular secondary metabolite. 
Differences in the xenobiotic detoxification capabilities of birds appears to be diet-related. Omnivorous species exhibit high detoxification capacity compared to species with a narrower diet (Fossi et al. 1995a; Fossi et al. 1995b; Liukkonen-Anttila et al. 2003; Rainio et al. 2012). Interspecific variation in detoxification capacity is usually related to differences in the mixed function oxidase or cytochrome P450 system, and mixed function oxidase activity is used as a biomarker to compare detoxification capacity among birds (Fossi et al. 1995b; Rainio et al. 2012).. In passerine birds, difference in mixed function oxidase activity is related to feeding habits and migratory status (Rainio et al. 2012) with, for example, insectivorous species having higher mixed function oxidase activity than granivorous species and migratory insectivores exhibiting the highest activity (Rainio et al. 2012). The detoxification capacity of nectar-feeding birds in terms of mixed function oxidase activity has not yet been explored.

Few studies have investigated the metabolic fate of ingested plant secondary metabolites in birds.. Birds either metabolise plant secondary metabolites through a combination of phase I and conjugation reactions or rapidly excrete the compounds unchanged. Ruffed grouse Bonasa umbellus fed high levels of the phenolic coniferyl-benzoate used hydrolysis, reduction and oxidation reactions to detoxify coniferyl-benzoate (Jakubas et al. 1993). In a related publication, Guglielmo et al. (1996) found that increased coniferyl-benzoate intake leads to an increase in excretion of glucuronic acid and ornithine (two major detoxification conjugates), associated with a $14 \%$ increase in energy requirements. Glucuronidation also plays a role in the detoxification of other phenolic compounds such as tannic acid in generalist (omnivorous) and specialist seed-eating birds (Ríos et al. 2012; Barceló et al. 2016). In contrast, cedar waxwings Bombycilla cedrorum excreted the cyanogenic glycoside, amygdalin, intact after ingestion (Struempf et al. 1999). If 
cyanogenic glycosides are not hydrolysed, no cyanide is released and ingestion has minimal or no toxic consequences. Lessner et al. (2015) found that hydrolysis of plant glucosides was undetectable in yellow-vented bulbuls (Pycnonotus xanthopygos) and house sparrows (Passer domesticus), and suggested that a low capacity in passerine birds to hydrolyse plant glucosides compared to mammals could explain the tolerance of birds to these compounds. Another group of secondary metabolites that appears to be excreted unchanged by birds is monoterpenes. The greater sage-grouse (Centrocercus urophasianus), which feeds on monoterpene rich sagebrush (Artemisia spp.), shows reduced absorption of these compounds and excretes monoterpenes unchanged in the faeces (Kohl et al. 2015).

\section{Conclusion}

Our results demonstrate the ability of white-bellied sunbirds and Cape white-eyes to metabolise the nectar alkaloid nicotine. Cape white-eyes mainly metabolised nicotine through the cotinine metabolic pathway, with norcotinine being the main metabolite present in the excreta, while whitebellied sunbirds excreted mainly nornicotine. Both species also utilized phase II conjugation reactions to detoxify nicotine, with white-eyes depending more on the mercapturic acid pathway to detoxify nicotine than sunbirds. Taken together, our results support the notion that different birds use different detoxification strategies to deal with secondary metabolites (Barcelo et al. 2016). Recently there has been considerable interest in possible adaptive functions of secondary metabolites in nectar, usually in studies involving insects (honeybees and bumblebees) (Stevenson et al. 2017). However, a large number of plant species are pollinated by nectar-feeding birds and understanding the effect of secondary metabolites on bird pollinators as well as the mechanisms 
used by nectar-feeding birds to escape the toxic effects of these secondary compounds is key in in understanding the adaptive functions of nectar secondary metabolites in plant-pollinator interactions. To our knowledge, this is the first study examining the metabolic fate of a plant secondary metabolite in nectar-feeding birds.

\section{Acknowledgements}

This research was funded by the University of Pretoria and the National Research Foundation (73671). We are grateful to Jan Cilliers Park and the Pretoria National Botanic Gardens for

permission to mist-net sunbirds and white-eyes under permit from the Gauteng Directorate of Nature Conservation. All bird care procedure and experimental protocols followed the institutional regulations of the Animal Use and Care Committee of the University of Pretoria (reference number: EC022-09). We thank Dr. M. Stander of the Central Analytical Facility at Stellenbosch University for conducting the nicotine metabolite analyses, Prof. Z. Apostolides for assistance with analysis and Dr F. Demares for advice on statistical procedure. 


\section{References}

Adler LS (2000) The ecological significance of toxic nectar. Oikos 91:409-420.

Adler LS, Seifert MG, Wink M, Morse GE (2012) Reliance on pollinators predicts defensive chemistry across tobacco species. Ecol Lett 15:1140-1148. doi: 10.1111/j.14610248.2012.01838.x

Almeida D, Maldonado E, Imran Khan I, et al (2016) Whole-genome identification, phylogeny, and evolution of the cytochrome P450 family 2 (CYP2) subfamilies in birds. Genome Biol Evol 8 (4): 1115-1131. doi: 10.1093/gbe/evw041

Au J, Marsh KJ, Wallis IR, Foley WJ (2013) Whole-body protein turnover reveals the cost of detoxification of secondary metabolites in a vertebrate browser. J Comp Physiol B 183:993-1003. doi: 10.1007/s00360-013-0754-3

Baldwin IT (2001) An ecologically motivated analysis of plant-herbivore interactions in native tobacco. Plant Physiol 127:1449-1458. doi: 10.1104/pp.010762

Barceló G, Ríos JM, Maldonado K, Sabat P (2016) Energetic costs and implications of the intake of plant secondary metabolites on digestive and renal morphology in two austral passerines. J Comp Physiol B 186:625-637. doi: 10.1007/s00360-016-0974-4

Beuchat CA, Calder III WA, Braun EJ (1990) The integration of osmoregulation and energy balance in hummingbirds. Physiol Zool 1059-1081.

Burn JH, Truelove LH, Burn I (1945) Antidiuretic action of nicotine. Br Med J 1:403.

Caviedes-Vidal E, McWhorter TJ, Lavin SR, et al (2007) The digestive adaptation of flying vertebrates: high intestinal paracellular absorption compensates for smaller guts. Proc Natl Acad Sci 104:19132-19137. 
Chen G, Giambrone NE, Dluzen DF, et al (2010) Glucuronidation genotypes and nicotine metabolic phenotypes: importance of functional UGT2B10 and UGT2B17 polymorphisms. Cancer Res 70:7543-7552. doi: 10.1158/0008-5472.CAN-09-4582

Dearing MD, Foley WJ, McLean S (2005) The influence of plant secondary metabolites on the nutritional ecology of herbivorous terrestrial vertebrates. Annu Rev Ecol Evol Syst 36:169-189. doi: 10.1146/annurev.ecolsys.36.102003.152617

Dearing MD, Mangione AM, Karasov WH (2001) Plant secondary compounds as diuretics: an overlooked consequence. Am Zool 41:890-901.

Dearing MD, Mangione AM, Karasov WH (2002) Ingestion of plant secondary compounds causes diuresis in desert herbivores. Oecologia 130:576-584.

De Souza EC, Silva Jr MRE (1977) The release of vasopressin by nicotine: further studies on its site of action. J Physiol 265:297-311.

Dieckhaus CM, Fernández-Metzler CL, King R, et al (2005) Negative ion tandem mass spectrometry for the detection of glutathione conjugates. Chem Res Toxicol 18:630-638.

Du Rand EE, Smit S, Beukes M, et al (2015) Detoxification mechanisms of honey bees (Apis mellifera) resulting in tolerance of dietary nicotine. Sci Rep 5:11779.

Fleming PA, Gray DA, Nicolson SW (2004a) Osmoregulatory response to acute diet change in an avian nectarivore: rapid rehydration following water shortage. Comp Biochem Physiol A Mol Integr Physiol 138:321-326. doi: 10.1016/j.cbpb.2004.04.003

Fleming PA, Gray DA, Nicolson SW (2004b) Circadian rhythm of water balance and aldosterone excretion in the whitebellied sunbird Nectarinia talatala. J Comp Physiol [B] 174:341-346. doi: 10.1007/s00360-004-0419-3 
Fleming PA, Nicolson SW (2003) Osmoregulation in an avian nectarivore, the whitebellied sunbird Nectarinia talatala: response to extremes of diet concentration. J Exp Biol 206:1845-1854. doi: 10.1242/jeb.00351

Fossi MC, Massi A, Lari L, et al (1995a) Interspecies differences in mixed function oxidase activity in birds: relationship between feeding habits, detoxfication activities and organochlorine accumulation. Environ Pollut 90:15-24.

Fossi MC, Massi A, Leonzio C, et al (1995b) Interspecific differences in mixed function oxidase activity in birds: a tool to identify "species at risk." Sci Total Environ 171:221-226.

Geerts S, Pauw A (2009) African sunbirds hover to pollinate an invasive hummingbirdpollinated plant. Oikos 118:573-579. doi: 10.1111/j.1600-0706.2009.17167.x

Gloss AD, Vassao DG, Hailey AL, et al (2014) Evolution in an ancient detoxification pathway is coupled with a transition to herbivory in the Drosophilidae. Mol Biol Evol 31:24412456. doi: 10.1093/molbev/msu201

Gray DA, Fleming PA, Nicolson SW (2004) Dietary intake effects on arginine vasotocin and aldosterone in cloacal fluid of whitebellied sunbirds (Nectarinia talatala). Comp Biochem Physiol A Mol Integr Physiol 138:441-449. doi: 10.1016/j.cbpb.2004.06.006

Guglielmo CG, William H. Karasov, Jakubas (1996) Nutritional costs of a plant secondary metabolite explain selective foraging by Ruffed Grouse. Ecology 77:1103-1115.

Hartman Bakken B, Sabat P (2006) Gastrointestinal and renal responses to water intake in the green-backed firecrown (Sephanoides sephanoides), a South American hummingbird. Am J Regul Integr Comp Physiol 291:R830-R386.

Hukkanen J, Jacob III P, Benowitz NL (2005) Metabolism and disposition kinetics of nicotine. Pharmacol Rev 57:79-115. doi: 10.1124/pr.57.1.3 
Jakubas WJ, Karasov WH, Guglielmo CG (1993) Ruffed Grouse tolerance and biotransformation of the plant secondary metabolite coniferyl benzoate. The Condor 95:625-640.

Johnson SD, Nicolson SW (2008) Evolutionary associations between nectar properties and specificity in bird pollination systems. Biol Lett 4:49-52.

Karasov WH (2011) Digestive physiology: a view from molecules to ecosystem. Am J Regul Integr Comp Physiol 301:R276-R284. doi: 10.1152/ajpregu.00600.2010

Karasov WH, Caviedes-Vidal E, Bakken BH, et al (2012) Capacity for absorption of watersoluble secondary metabolites greater in birds than in rodents. PLoS ONE 7:e32417. doi: 10.1371/journal.pone.0032417

Karasov WH, Martínez del Rio C (2007) Physiological ecology: how animals process energy, nutrients, and toxins. Princeton University Press, Princeton

Kessler D, Bhattacharya S, Diezel C, et al (2012) Unpredictability of nectar nicotine promotes outcrossing by hummingbirds in Nicotiana attenuata: variability in nectar nicotine promotes outcrossing. Plant J 71:529-538. doi: 10.1111/j.1365-313X.2012.05008.x

Kessler D, Diezel C, Baldwin IT (2010) Changing pollinators as a means of escaping herbivores. Curr Biol 20:237-242. doi: 10.1016/j.cub.2009.11.071

Kohl KD, Pitman E, Robb BC, et al (2015) Monoterpenes as inhibitors of digestive enzymes and counter-adaptations in a specialist avian herbivore. J Comp Physiol B 185:425-434. doi: $10.1007 / \mathrm{s} 00360-015-0890-\mathrm{z}$

Lerch-Henning S, Nicolson SW (2013) Bird pollinators differ in their tolerance of a nectar alkaloid. J Avian Biol 44:408-416. doi: 10.1111/j.1600-048X.2013.00079.x 
Lerch-Henning S, Nicolson SW (2015) Effects of nicotine on the digestive performance of nectar-feeding birds reflect their relative tolerance to this alkaloid. Comp Biochem Physiol A Mol Integr Physiol 190:47-53. doi: 10.1016/j.cbpa.2015.08.015

Lessner KM, Dearing MD, Izhaki I, et al (2015) Small intestinal hydrolysis of plant glucosides: higher glucohydrolase activities in rodents than passerine birds. J Exp Biol 218:26662669. doi: $10.1242 / \mathrm{jeb} .121970$

Liska DJ (1998) The detoxification enzyme systems. Altern Med Rev 3:187-98.

Lushchak VI (2012) Glutathione homeostasis and functions: potential targets for medical interventions. J Amino Acids 2012:1-26. doi: 10.1155/2012/736837

Mangione AM, Dearing MD, Karasov WH (2004) Creosote bush (Larrea tridentata) resin increases water demands and reduces energy availability in desert woodrats (Neotoma lepida). J Chem Ecol 30:1409-1429.

Martínez del Rio C, Schondube JE, McWhorter TJ, Herrera LG (2001) Intake responses in nectar feeding birds: digestive and metabolic causes, osmoregulatory consequences, and coevolutionary effects. Am Zool 41:902-915.

McWhorter TJ, del Rio CM (1999) Food ingestion and water turnover in hummingbirds: how much dietary water is absorbed? J Exp Biol 202:2851-2858.

McWhorter TJ, del Rio CM, Pinshow B (2003) Modulation of ingested water absorption by Palestine sunbirds: evidence for adaptive regulation. J Exp Biol 206:659-666.

Meger M, Meger-Kossien I, Schuler-Metz A, et al (2002) Simultaneous determination of nicotine and eight nicotine metabolites in urine of smokers using liquid chromatographytandem mass spectrometry. J Chromatogr B 778:251-261. 
Miller EI, Norris H-RK, Rollins DE, et al (2010) A novel validated procedure for the determination of nicotine, eight nicotine metabolites and two minor tobacco alkaloids in human plasma or urine by solid-phase extraction coupled with liquid chromatographyelectrospray ionization-tandem mass spectrometry. J Chromatogr B 878:725-737.

Munro AW, Girvan HM, Mason AE, et al (2013) What makes a P450 tick? Trends Biochem Sci 38:140-150. doi: 10.1016/j.tibs.2012.11.006

Napier KR, Fleming PA, McWhorter TJ (2014) Mistletoebirds and xylose: Australian frugivores differ in their handling of dietary sugars. Physiol Biochem Zool 87:445-455. doi: $10.1086 / 675493$

Napier KR, Purchase C, McWhorter TJ, et al (2008) The sweet life: diet sugar concentration influences paracellular glucose absorption. Biol Lett 4:530-533. doi: $10.1098 /$ rsbl.2008.0253

Nicolson SW, Fleming PA (2014) Drinking problems on a "simple"diet: physiological convergence in nectar-feeding birds. J Exp Biol 217:1015-1023.

Nicolson SW, Fleming PA (2003) Energy balance in the whitebellied sunbird Nectarinia talatala: constraints on compensatory feeding, and consumption of supplementary water. Funct Ecol 17:3-9.

Purchase C, Napier KR, Nicolson SW, et al (2013a) Gastrointestinal and renal responses to variable water intake in whitebellied sunbirds and New Holland honeyeaters. J Exp Biol 216:1537-1545.

Purchase C, Nicolson SW, Fleming PA (2013b) Salt intake and regulation in two passerine nectar drinkers: white-bellied sunbirds and New Holland honeyeaters. J Comp Physiol B $183: 501-510$. 
Rainio MJ, Kanerva M, Wahlberg N, et al (2012) Variation of basal EROD activities in ten passerine bird species - relationships with diet and migration status. PLoS ONE 7:e33926. doi: 10.1371/journal.pone.0033926

Rangiah K, Hwang W-T, Mesaros C, et al (2011) Nicotine exposure and metabolizer phenotypes from analysis of urinary nicotine and its 15 metabolites by LC-MS. Bioanalysis 3:745761. doi: 10.4155/bio.11.42

Rinaldi R, Eliasson E, Swedmark S, Morgenstern R (2002) Reactive intermediates and the dynamics of glutathione transferases. Drug Metab Dispos 30:1053-1058.

Ríos JM, Mangione AM, Marone L (2012) Tolerance to dietary phenolics and diet breadth in three seed-eating birds: implications for graminivory. J Exp Zool Part Ecol Genet Physiol 317:425-433. doi: 10.1002/jez.1735

Rooke IJ, Bradshaw SD, Langworthy RA (1983) Aspects of the water, electrolyte and carbohydrate physiology of the silvereye, Zosterops lateralis (Aves). Aust J Zool 31:695-704.

Sorensen JS, Dearing MD (2006) Efflux transporters as a novel herbivore counter mechanism to plant chemical defenses. J Chem Ecol 32: 1181. doi:10.1007/s10886-006-9079-y

Sorensen JS, McLister JD, Dearing MD (2005) Plant secondary metabolites compromise the energy budgets of specialist and generalist mammalian herbivores. Ecology 86:125-139.

Steppuhn A, Gase K, Krock B, et al (2004) Nicotine's defensive function in nature. PLoS Biol 2:e217. doi: 10.1371/journal.pbio.0020217

Stevenson PC, Nicolson SW, Wright GA (in press) Plant secondary metabolites in nectar: impacts on pollinators and ecological functions. 
Struempf HM, Schondube JE, Martínez del Rio C (1999) The cyanogenic glycoside amygdalin does not deter consumption of ripe fruit by cedar waxings. The Auk 116:749-758.

Tadmor-Melamed H, Markman S, Arieli A, et al (2004) Limited ability of Palestine sunbirds Nectarinia osea to cope with pyridine alkaloids in nectar of tree tobacco Nicotiana glauca. Funct Ecol 18:844-850. 


\section{Tables}

Table 1 Sugar and nicotine intake of sunbirds and white-eyes. Sugar intake (g) and nicotine intake $(\mu \mathrm{g})$ of sunbirds $C$. talatala $(n=8)$ and white-eyes $Z$. virens $(n=9)$ feeding on a sucrose diet of $0.63 \mathrm{M}$ with different nicotine concentrations $(0,0.5,5$ and $50 \mu \mathrm{M}$ of nicotine $)$ for a duration of $6 \mathrm{~h}$.

\begin{tabular}{|l|c|c|c|c|}
\hline \multicolumn{1}{|c|}{ Species } & \multicolumn{2}{|c|}{ Sunbirds } & \multicolumn{2}{c|}{ White-eyes } \\
\hline \multicolumn{1}{|c|}{ Diet $(\mathbf{0 . 6 3} \mathbf{M})$} & $\begin{array}{c}\text { Sugar intake } \\
(\mathbf{g})\end{array}$ & $\begin{array}{c}\text { Nicotine intake } \\
(\boldsymbol{\mu g})\end{array}$ & $\begin{array}{c}\text { Sugar intake } \\
(\mathbf{g})\end{array}$ & $\begin{array}{c}\text { Nicotine intake } \\
(\boldsymbol{\mu g})\end{array}$ \\
\hline Control & $1.38 \pm 0.05$ & - & $0.99 \pm 0.14$ & - \\
$0.5 \mu \mathrm{M}$ nicotine & $1.25 \pm 0.08$ & $0.47 \pm 0.03$ & $1.07 \pm 0.12$ & $0.40 \pm 0.05$ \\
$5 \mu \mathrm{M}$ nicotine & $1.19 \pm 0.08$ & $4.48 \pm 0.30$ & $1.11 \pm 0.09$ & $4.17 \pm 0.32$ \\
$50 \mu \mathrm{M}$ nicotine & $0.18 \pm 0.02$ & $6.81 \pm 0.70$ & $0.18 \pm 0.02$ & $6.76 \pm 0.64$ \\
\hline
\end{tabular}


Table 2 Food and nicotine intake vs cloacal fluid output and nicotine excretion. Food intake $(\mathrm{ml})$, nicotine intake $(\mu \mathrm{g}$, amounts per individual and mean $\pm \mathrm{SE}$ ), cloacal fluid $(\mathrm{CF})$ excretion $(\mathrm{ml})$ and nicotine recovered in the cloacal fluid ( $\mu \mathrm{g}$, amounts per individual and mean $\pm \mathrm{SE}$ ) of sunbirds $C$. talatala (SB, $n=4$ ) and white-eyes $Z$. virens (WE, $n=4$ ) feeding on $0.25 \mathrm{M}$ or $1 \mathrm{M}$ sucrose containing $50 \mu \mathrm{M}$ nicotine, for a duration of $6 \mathrm{~h}$.

\begin{tabular}{|c|c|c|c|c|c|c|c|}
\hline \multirow{3}{*}{$\begin{array}{c}\text { Species } \\
\text { SB }\end{array}$} & \multirow{3}{*}{$\begin{array}{c}\text { Sucrose (M) } \\
0.25\end{array}$} & \multicolumn{3}{|c|}{ INTAKE } & \multicolumn{3}{|c|}{ OUTPUT } \\
\hline & & $\begin{array}{c}\text { Food } \\
(\mathrm{ml})\end{array}$ & \multicolumn{2}{|c|}{ Nicotine $(\mu \mathrm{g})$} & $\begin{array}{c}\mathbf{C F} \\
(\mathbf{m l})\end{array}$ & \multicolumn{2}{|c|}{ Nicotine $(\mu \mathrm{g})$} \\
\hline & & 10.47 & 88.724 & \multirow{4}{*}{$94.92 \pm 1.8$} & 5.40 & 0.023 & \multirow{4}{*}{$0.02 \pm 0.0$} \\
\hline SB & 0.25 & 11.43 & 96.831 & & 7.20 & 0.022 & \\
\hline SB & 0.25 & 11.46 & 97.131 & & 8.60 & 0.025 & \\
\hline SB & 0.25 & 11.44 & 96.981 & & 8.00 & 0.027 & \\
\hline SB & 1 & 3.70 & 31.376 & \multirow{4}{*}{$35.58 \pm 3.6$} & 2.00 & 0.021 & \multirow{4}{*}{$0.02 \pm 0.0$} \\
\hline SB & 1 & 4.20 & 35.580 & & 1.80 & 0.021 & \\
\hline SB & 1 & 3.32 & 28.148 & & 1.60 & 0.031 & \\
\hline SB & 1 & 5.57 & 47.214 & & 2.60 & 0.022 & \\
\hline WE & 0.25 & 10.05 & 77.990 & \multirow{4}{*}{$66.13 \pm 4.7$} & 7.60 & 0.036 & \multirow{4}{*}{$0.03 \pm 0.0$} \\
\hline WE & 0.25 & 8.12 & 63.052 & & 6.40 & 0.023 & \\
\hline WE & 0.25 & 6.77 & 52.544 & & 4.60 & 0.023 & \\
\hline WE & 0.25 & 9.14 & 70.934 & & 7.60 & 0.031 & \\
\hline WE & 1 & 2.66 & 20.642 & \multirow{4}{*}{$20.68 \pm 3.9$} & 1.60 & 0.043 & \multirow{4}{*}{$0.04 \pm 0.0$} \\
\hline WE & 1 & 2.86 & 22.218 & & 1.80 & 0.043 & \\
\hline WE & 1 & 1.15 & 8.932 & & 1.80 & 0.026 & \\
\hline WE & 1 & 3.98 & 30.926 & & 2.60 & 0.044 & \\
\hline
\end{tabular}


Table 3 Nicotine and nicotine-derived metabolites detected in the excreta of sunbirds and white-eyes. Sunbirds $C$. talatala $(n=8)$ and white-eyes $Z$. virens $(n=8)$ were exposed to sucrose solutions $(0.25$ and $1 \mathrm{M})$ containing $50 \mu \mathrm{M}$ nicotine for $6 \mathrm{~h}$ before excreta were collected. Excreta samples were analysed for nicotine and nicotine-derived metabolites using UPLC/MS/MS. The molecular formula and the molecular ion $[\mathrm{M}+\mathrm{H}]^{+}$of each compound are indicated. Nicotine and nicotine-derived metabolites detected in excreta samples are expressed as a percentage (\%) of the total amount of nicotine ingested. The values reported in bold are significantly different between the two species ( $t$-test for independent samples). GSH: Glutathione. Nicotine-NAC: Nicotine-Nacetylcysteine.

\begin{tabular}{|c|c|c|c|c|c|c|c|}
\hline \multirow{2}{*}{$\begin{array}{l}\text { Name of } \\
\text { Compound }\end{array}$} & \multirow{2}{*}{$\begin{array}{l}\text { Molecular } \\
\text { formula }\end{array}$} & \multirow{2}{*}[\mathbf{M}+\mathbf{H}]{$^{+}$} & \multicolumn{2}{|c|}{$\%$ of ingested nicotine dose } & \multicolumn{2}{|c|}{$\begin{array}{l}\text { Statistical } \\
\text { Results }\end{array}$} & \multirow{2}{*}{ Reference } \\
\hline & & & Sunbirds & White-eyes & $\mathbf{t}_{14}$ & $\boldsymbol{P}$ & \\
\hline Nicotine & $\mathrm{C}_{10} \mathrm{H}_{14} \mathrm{~N}_{2}$ & 163.11 & 0.05 & 0.13 & - & - & Miller et al. 2010 \\
\hline Norcotinine & $\mathrm{C}_{9} \mathrm{H}_{10} \mathrm{~N}_{2} \mathrm{O}$ & 162.11 & 8.65 & 39.57 & -5.86 & 0.001 & $\begin{array}{l}\text { Hukkanen et } \\
\text { al.2005 }\end{array}$ \\
\hline $\begin{array}{l}\text { Cotinine } \\
\text { methonium ion }\end{array}$ & $\mathrm{C}_{11} \mathrm{H}_{15} \mathrm{~N}_{2} \mathrm{O}$ & 189.16 & 9.07 & 7.57 & 2.06 & 0.058 & $\begin{array}{l}\text { Hukkanen et al. } \\
2005\end{array}$ \\
\hline Nornicotine & $\mathrm{C}_{9} \mathrm{H}_{12} \mathrm{~N}_{2}$ & 148.06 & 0.88 & 1.72 & -0.52 & 0.612 & Rangiah 2011 \\
\hline $\begin{array}{l}\text { Nornicotine- } \\
\text { glucuronide }\end{array}$ & $\mathrm{C}_{15} \mathrm{H}_{21} \mathrm{~N}_{2} \mathrm{O}_{6}$ & 325.11 & 8.85 & 12.5 & 1.67 & 0.116 & $\begin{array}{l}\text { Meger et al. } 2002 \\
\text { Rangiah } 2011\end{array}$ \\
\hline $\begin{array}{l}\text { Norcotinine- } \\
\text { glucuronide }\end{array}$ & $\mathrm{C}_{15} \mathrm{H}_{19} \mathrm{~N}_{2} \mathrm{O}_{3}$ & 277.09 & 3.38 & 1.86 & -0.11 & 0.915 & $\begin{array}{l}\text { Meger et al. } 2002 \\
\text { Rangiah } 2011\end{array}$ \\
\hline GSH & $\mathrm{C}_{10} \mathrm{H}_{17} \mathrm{~N}_{3} \mathrm{O}_{6} \mathrm{~S}$ & 308.17 & 0.11 & 12.2 & -3.66 & 0.003 & $\begin{array}{l}\text { Dieckhaus et al. } \\
\text { 2005) }\end{array}$ \\
\hline Cotinine-GSH & $\mathrm{C}_{20} \mathrm{H}_{29} \mathrm{~N}_{5} \mathrm{O}_{6} \mathrm{~S}$ & 482.29 & 5.44 & 4.22 & 1.46 & 0.167 & $\begin{array}{l}\text { Dieckhause et al. } \\
2005\end{array}$ \\
\hline Nicotine-NAC & $\mathrm{C}_{16} \mathrm{H}_{24} \mathrm{~N}_{4} \mathrm{O}_{3} \mathrm{~S}_{2}$ & 386.29 & 1.19 & 4.27 & -3.00 & 0.010 & Gloss et al. 2014 \\
\hline
\end{tabular}

\footnotetext{
${ }^{a}$ Molecular ions corresponding to nornicotine-glucuronide were detected at three different retention times and further analysis is required to confirm the identity of the compounds eluting at these retention times
} 


\section{Figure legends}

\section{Fig. 1 Effect of dietary nicotine on food intake and cloacal fluid output}

The volume of food consumed (ml) and cloacal fluid excreted (ml) in (a) white-bellied sunbirds C. talatala $(n=8)$ and (b) Cape white-eyes Z. virens $(n=9)$. Birds were fed four test diets $(0,0.5$, 5 or $50 \mu \mathrm{M}$ nicotine in $0.63 \mathrm{M}$ sucrose) for $6 \mathrm{~h}$. Bars are mean values + SE. Significant differences $(p \leq 0.05)$ are indicated by different letters; correspondence of at least one letter indicates no significant difference.

Fig. 2 Effect of nicotine on the osmolality of cloacal fluid and the ratio of cloacal fluid to food intake

Effect of nicotine on (a) osmolality of cloacal fluid (mOsmol/kg) and (b) the proportion of cloacal fluid (ml) to food intake (ml) of white-bellied sunbirds $C$. talatala $(n=8)$ and Cape white-eyes $Z$. virens $(n=9)$. Birds were exposed to four test diets $(0,0.5,5$ or $50 \mu \mathrm{M}$ nicotine in $0.63 \mathrm{M}$ sucrose $)$

for $6 \mathrm{~h}$. Bars are mean values $+\mathrm{SE}$ and significant differences $(\mathrm{p} \leq 0.05)$ are indicated by different letters; correspondence of at least one letter indicates no significant difference.

\section{Fig. 3 Conversion of nicotine to its major metabolites in nectar-feeding birds}

Relative amounts (\%) of metabolites found in the excreta of sunbirds $C$. talatala and white-eyes Z. virens are indicated in parentheses. Diagram adapted from Hukkanen et al. (2005) and Gloss et al. (2014). GSH: Glutathione. Nicotine-NAC: Nicotine-N-acetylcysteine. 

a) Sunbirds
b) White-eyes

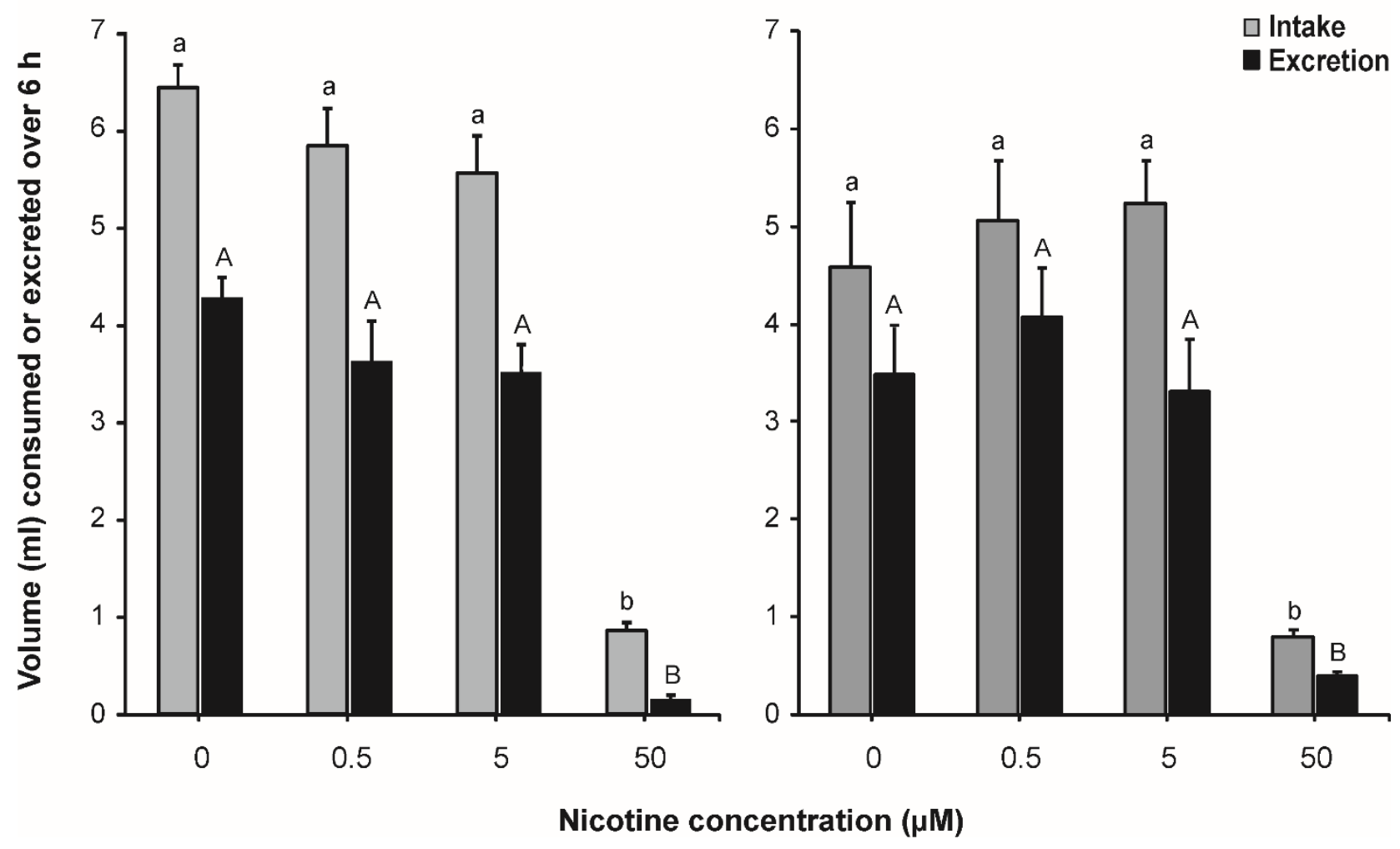

Figure 1. 
a)

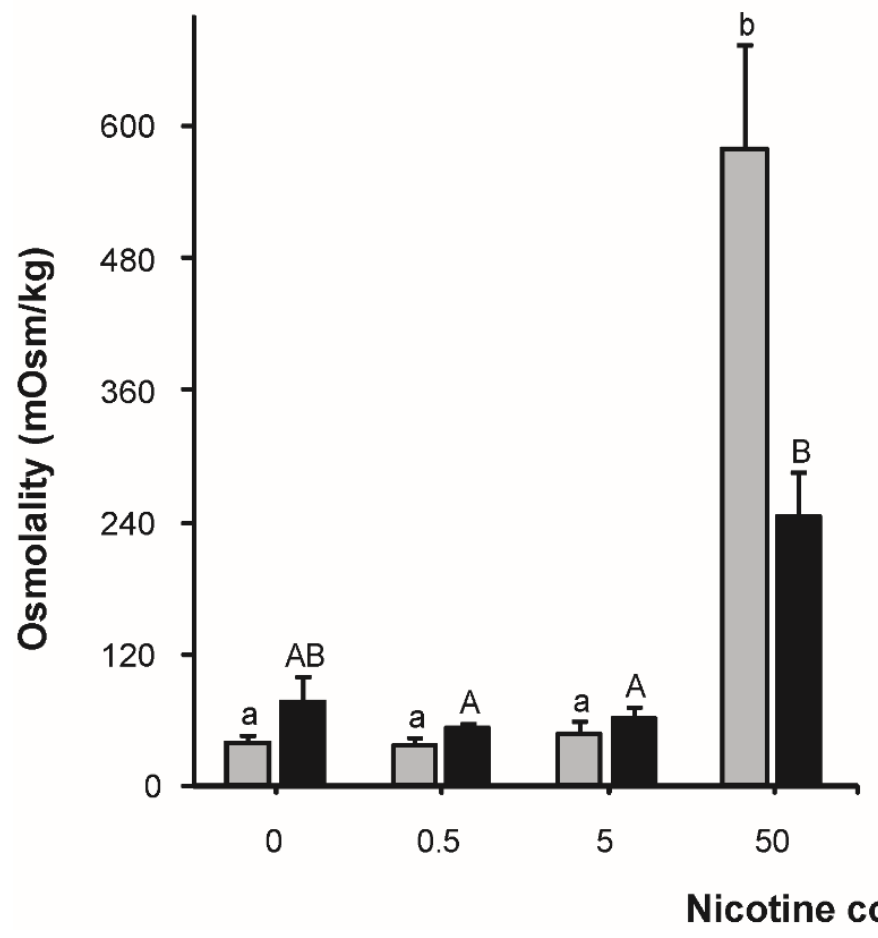

b)

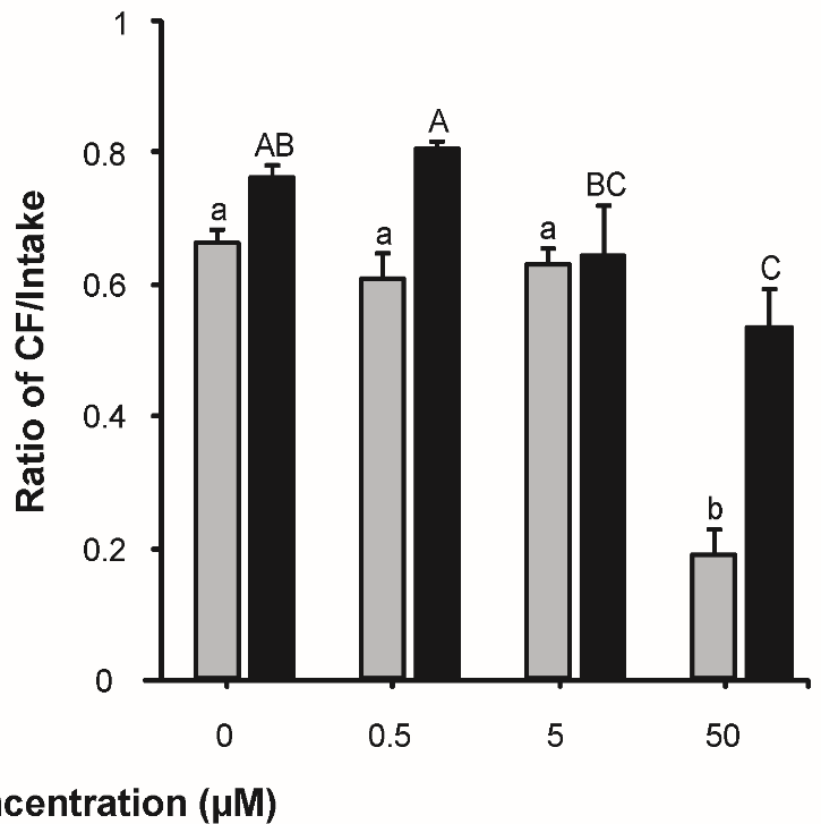

Figure 2. 


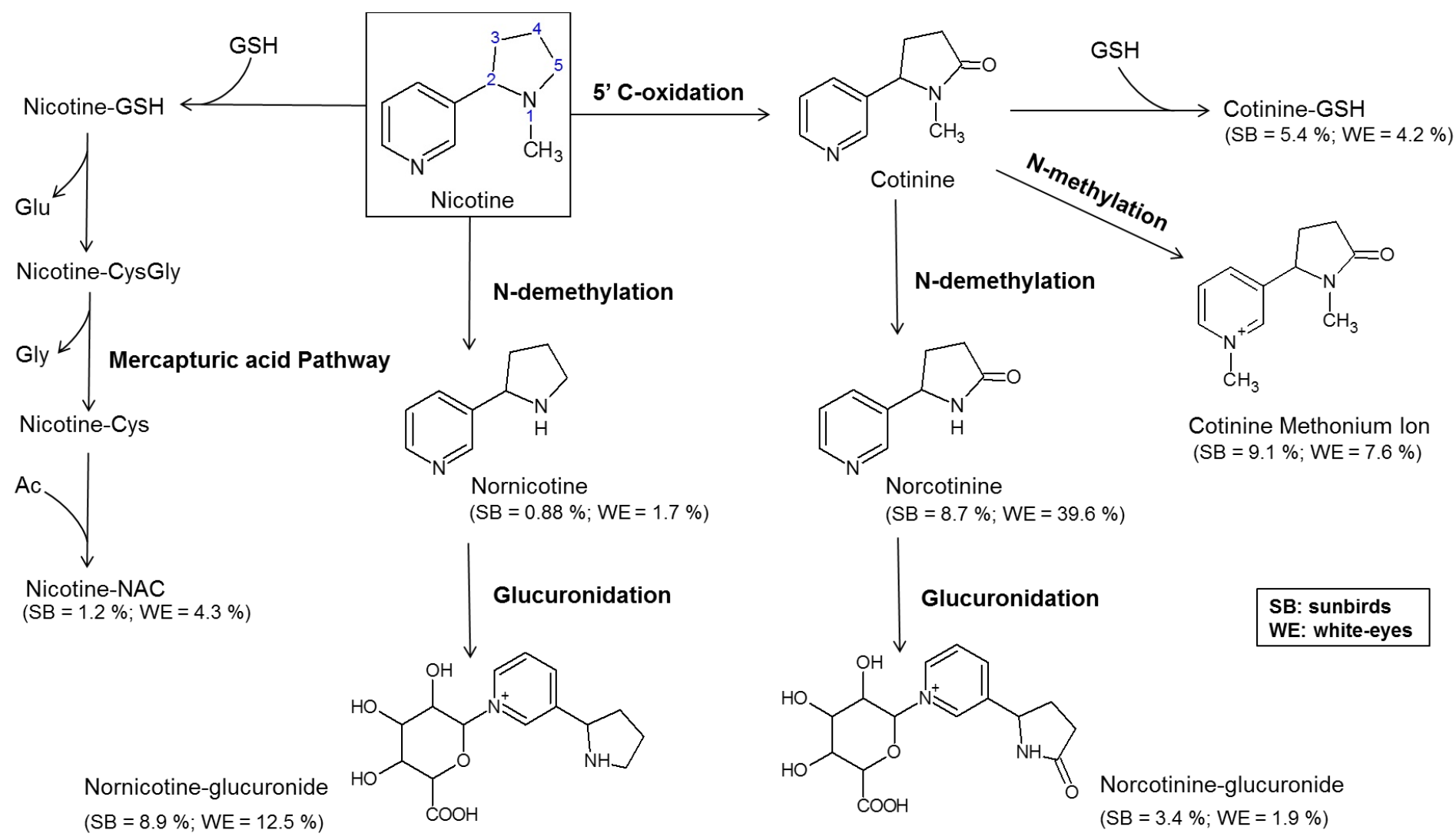

\section{Figure 3.}

